\title{
Exploring the Impact of Sexed Semen on the Structure of the Dairy Industry
}

\author{
A. De Vries, ${ }^{\star 1}$ M. Overton,† J. Fetrow,‡ K. Leslie,§ S. Eicker,\# and G. Rogers\| \\ *Department of Animal Sciences, University of Florida, Gainesville 32611 \\ †Department of Population Health, University of Georgia, Athens 30602 \\ ‡Department of Veterinary Population Medicine, University of Minnesota, St. Paul 55108 \\ §Department of Population Medicine, University of Guelph, Ontario, Canada N1G 2W1 \\ \#Valley Agricultural Software, King Ferry, NY 13081 \\ ||Department of Animal Science, University of Tennessee, Knoxville 37996
}

\section{ABSTRACT}

Widespread commercial application of sexed semen is expected within the next decade because of continued improvements in fertility of sexed semen and sorting capacity. The objective of this study was to explore the potential impact of widespread application of sexed semen on the structure of the dairy industry in the United States. Historically, female offspring from all heifers and cows were needed to produce enough dairy replacement heifers to replace culled cows. The use of sexed semen allows for a decoupling of breeding decisions necessary to obtain an adequate supply of dairy replacement heifers from those needed to achieve pregnancies needed to start new lactations. Application of sexed semen allows dairy producers to select among their herds' potential dams and produce dairy replacement heifers from only the genetically superior animals. The rate of genetic progress is expected to increase, but not more than $15 \%$ of the rate of gain accomplished through sire selection achieved through conventional (nonsexed) artificial insemination breeding. The supply of dairy replacement heifers is expected to grow to meet and temporarily exceed current demand, resulting in reduced prices for dairy replacement heifers. Consequently, herd turnover rates are expected to increase slightly, and herd expansions may accelerate. The rate of consolidation of dairy farms is expected to increase. Widespread application of sexed semen may temporarily increase the supply of milk, which would result in lower milk prices. The cost of milk production will be reduced as well. Many breeding options exist for the genetically poorer cows in the herd. The optimal breeding mix depends on the value of the various kinds of calves that could be produced. More crossbred calves

Received July 20, 2007.

Accepted October 2, 2007.

${ }^{1}$ Corresponding author: devries@ufl.edu for beef production may be produced; however, a market for these crossbred calves is not well established. Increased specialization is expected with more dairy producers deciding not to raise their own heifers but to purchase replacements. Other dairy farms might specialize in producing genetically superior dairy replacement heifers for sale. Depending on the value of calves not raised for replacements, artificial insemination organizations might market beef conventional semen or beef male sexed semen to dairy farms. The use of sexed semen should lower the cost of progeny-testing programs and embryo transfer and enhance the value of genetic markers. Eventually, the economic benefits from the use of sexed semen will be passed on to consumers.

Key words: sexed semen, sex, dairy industry

\section{INTRODUCTION}

Sexed semen is semen in which the fractions of $\mathrm{X}$ bearing and Y-bearing sperm have been modified from the natural mix through sorting and selection. The goal of sexed semen is to produce a calf of a specific sex. The consequences of the ability to choose the sex of an animal's offspring on livestock production has been discussed since at least 1970 when a major scientific symposium on sexing sperm was held at the Pennsylvania State University (Kiddy and Hafs, 1971). Advantages for dairy producers would include an increased supply of replacement heifers, thereby reducing dairy heifer purchase and sale prices and easier within-herd growth (Weigel, 2004). Other possible benefits are increased effectiveness of AI progeny testing programs, in-vitro embryo production programs, and multiple ovulation and embryo transfer (MOET) schemes (Weigel, 2004). Continued advances in semen sorting technology, improved fertility of sexed semen, and increased marketing will likely increase the use of sexed semen in the dairy industry in the next decade on a much wider scale than before. 
The only commercially viable method currently available to the dairy industry (as of July, 2007) appears to be based on flow cytometrical cell sorting for DNA content of sperm (Seidel and Garner, 2002; Weigel, 2004; Moore and Thatcher, 2006; Wheeler et al., 2006; Seidel, 2007). The method works by staining sperm with a DNA-binding fluorescent dye. The bovine Y-chromosome bearing sperm contain $3.8 \%$ less DNA than the $\mathrm{X}$-chromosome bearing sperm. This allows for their separation by a fluorescence-activated cell sorter (Moore and Thatcher, 2006; Garner, 2006; Seidel, 2007). The method is fairly accurate with 85 to $95 \%$ of the sperm containing the desired chromosome (Garner and Seidel, 2003). Sorting is relatively slow, and fertility of sexed sperm is typically lower compared with conventional sperm (Garner and Seidel, 2003). Some studies with sexed sperm, mostly with $2 \times 10^{6}$ sexed sperm per straw, resulted in risks of conception that have been 60 to $80 \%$ of the unsorted control, mostly with $20 \times 10^{6}$ sperm per straw. Sperm dose alone does not explain the reduced fertility, however (Garner and Seidel, 2003). When reproductive management is excellent, risks of conception for breeding heifers are only slightly lower than normal using low doses of sexed semen. Risks of conception with sexed semen in lactating dairy cows can be similar to that of conventional semen if cows have completely normal reproductive characteristics (Seidel, 2007).

Semen cell sorting technology is continuously being improved (Garner, 2006; Seidel, 2007), and it is plausible that commercially attractive sexed semen will be more widely available and used in the near future. An exploration of the possible effects of the use of sexed semen on the dairy industry in the United States is not available in the literature. The objective of this study is therefore to explore the potential impact of widely used sexed semen on the structure of the dairy industry. Key underlying assumptions for this study are that the fertility of sexed semen approaches that of conventional semen, the calf has the desired sex in at least $90 \%$ of the cases, performance of calves born from sexed semen is similar to calves born from conventional semen, sexed semen from popular sires is widely available, and the price of sexed semen is not a limitation to its widespread adoption.

\section{RESULTS AND DISCUSSION}

\section{Decoupling of Breeding for Replacements from Breeding to Start New Lactations}

The United States had approximately 9.1 million adult dairy cows during the last quarter of 2006 (USDANASS, 2007). This number is very similar to that at the start of 2006 when of the 9.1 million cows, 3.6 million cows $(40 \%)$ were in their first lactation. Dairy re- placement heifers over $500 \mathrm{lb}(227 \mathrm{~kg})$ were estimated at 4.3 million animals on January 1,2006. Dairy heifers expected to calve in 2006 were estimated at 2.9 million, or 31.9 heifers per 100 cows. Collectively, this implies an annual US turnover rate of approximately $32 \%$.

To maintain this population of approximately 9.1 million cows, cows and heifers are bred to natural service dairy bulls and by dairy AI. Beef semen is currently minimally used in dairy cattle breedings. Current sales of dairy AI semen are around 16 million units per year (Weigel, 2004; Moore and Thatcher, 2006), which accounts for an estimated 60 to $80 \%$ of all pregnancies. This semen is virtually all natural conventional semen from dairy breeds. The economics of dairy cattle replacement has meant that essentially all possible pregnancies were needed to produce enough dairy heifer calves to replace culled cows. In addition, pregnancies are needed to start new lactations and boost milk production.

The annual herd turnover rate (number of cows left herd/average number of cows in the herd) and the maximum number of dairy heifer calves that can be produced each year have been in close agreement. Furthermore, the price of dairy heifers is very sensitive to supply and demand. Since 2004, restrictions on the import of dairy heifers from Canada have reduced the annual supply of replacement heifers. Ongoing expansion in especially the larger herds has maintained demand. Consequently, the limiting supply of dairy replacement heifers and the demand for heifers to maintain or expand herds have resulted in dairy replacement heifer prices that have been significantly above their cost of production in the past several years.

The plentiful availability of economically priced, genetically competitive sexed semen allows for more dairy heifer calves to be born than are needed to replace (unavoidably) culled cows. This decoupling between breeding to obtain replacement heifers and breeding to start new lactations is expected to have significant effects on reproductive management decisions and the structure of the dairy industry.

\section{Effects on Heifer Price, Milk Price, and Cull Cow Price}

Historically, milk prices, pregnant replacement heifer prices, and cull cow prices have been positively related. Over the last $10 \mathrm{yr}$, milk prices have remained on average constant, but cull cow prices and replacement prices have gradually increased (Figure 1). Disconnect between these prices is thought to be largely due to the accelerated expansion of large dairy farms, primarily in the western United States, since the mid1990s. The choice of using heifers to expand herds has 


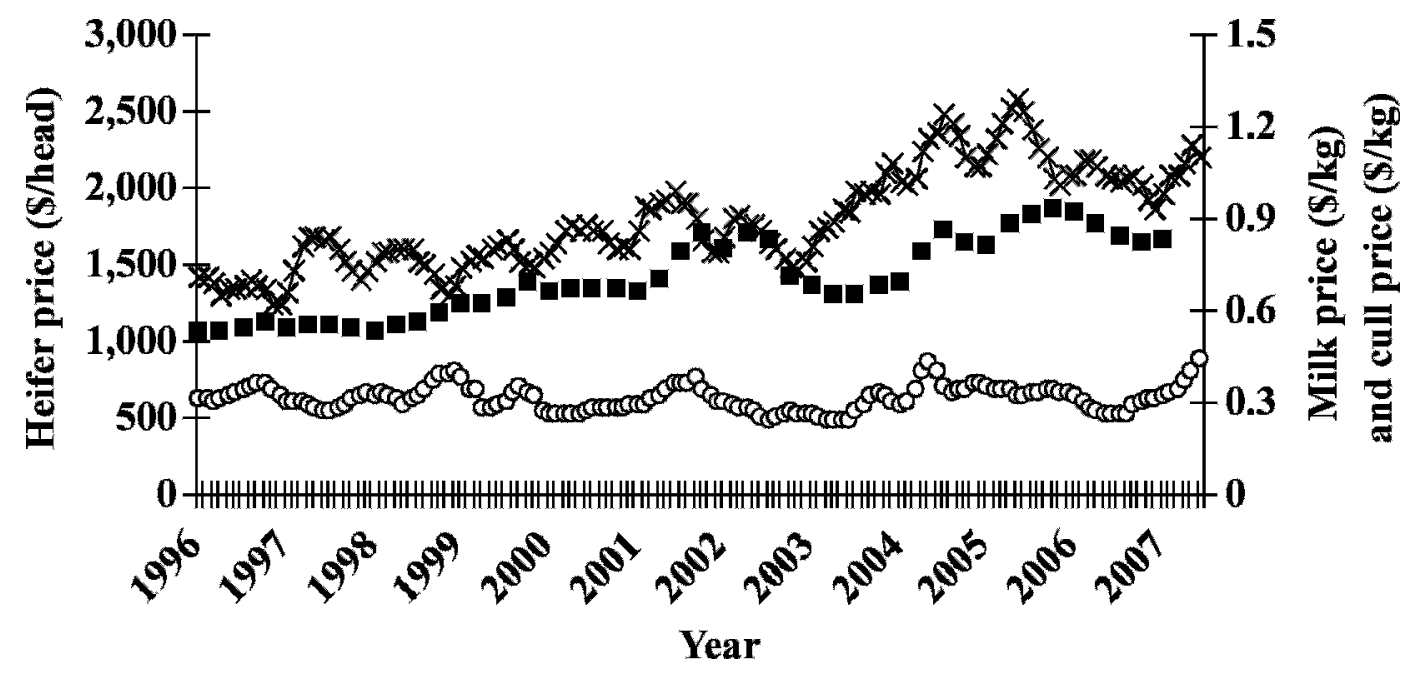

Figure 1. Average heifer prices $(\mathbf{\square}, \$ /$ head), milk prices $(\bigcirc, \$ / \mathrm{kg})$, and cull cow prices $(\times, \$ / \mathrm{kg}$ BW) in the United States from January 1996 to June 2007. Source: USDA-NASS Agricultural Prices. Heifer prices available at http://www.aae.wisc.edu/future/; Milk prices and cull cow prices available at http://www.nass.usda.gov

been primarily due to 2 reasons. First, few dairy farms in the west have retired from business; therefore, few mature cows have been available locally for relocation. Second, compared with lactating animals that need to be milked, it is easier to assemble truckloads of pregnant heifers and move them long distances.

Dairy Heifer Price. The cost to raise a dairy replacement heifer calf to first calving, including the price of the calf, has been estimated from approximately $\$ 1,200$ to $\$ 1,600$ (Tozer et al., 1999; Karzes, 2005). Because of strong demand and limited supply in the last several years, the purchase price of dairy heifers has been significantly higher, approximately $\$ 1,500$ to $\$ 2,300$ (DairyBusiness Communications, 2007). The demand for pregnant heifers has created a ripple effect down to the level of the newborn calf. Newborn dairy calves have been commanding prices as high as $\$ 500$ to $\$ 600$ at times, but more commonly in the area of $\$ 400$ to $\$ 450$ (DairyBusiness Communications, 2007).

Initially, the widespread use of sexed semen will increase the supply of dairy replacement heifers to meet the strong demand. As the supply of replacement heifers rises and meets the demand, the purchase price of heifers is expected to decrease and stabilize around the purchase price of the calf, rearing costs, and a modest profit for the heifer raiser, likely within the range of $\$ 1,300$ to $\$ 1,500$. The price of female newborn calves will decrease as well, assuming average milk prices.

The decrease in heifer prices will cause the average value of a cow in the herd to decrease. Using the simulation model of De Vries (2006), it was estimated that the value of the average cow in the herd may drop $\$ 60$ to $\$ 70$ per $\$ 100$ decrease in heifer price. Thus, the value of an average cow might decrease by $\$ 200$ to $\$ 300$. For dairy farms whose balance sheets have been valuing cows based on the market value, there will be an appearance of sudden loss of assets and equity. This decrease may be enough to cause loan officers and banks to tighten their lending practices, potentially resulting in a small braking effect on the rate of herd expansions.

Herd Turnover Rates. The annual herd turnover rate is expected to increase because the difference between the prices of heifers and cull cows will be reduced with the widespread application of sexed semen. Rational dairy producers will increase their herd turnover rates because it will be worth replacing more cows of marginal value that are being retained under current market conditions.

For example, given a set of realistic assumptions about prices and cow performance (De Vries, 2006), calculations that included optimal replacement management showed that herd turnover rates increased from approximately 32 to $42 \%$ when heifer prices decreased from $\$ 1,900$ to $\$ 1,300$ per head. When the heifer price was $\$ 1,900$, changes in milk prices affected herd turnover rates less than when the heifer price was lower. The lowest herd turnover rate $(30 \%)$ was obtained with a $\$ 1,900$ heifer price and a $\$ 0.26 / \mathrm{kg}(\$ 11.80 /$ cwt) milk prices. The highest herd turnover rate $(44 \%)$ was obtained with a $\$ 1,300$ heifer price and a $\$ 0.32 / \mathrm{kg}$ $(\$ 14.52 / \mathrm{cwt})$ milk price. These patterns were the same when unavoidable herd turnover rates were smaller or greater, although total herd turnover rates were accordingly somewhat smaller or greater, respectively. Herd turnover rates are farm specific, but these trends in 
herd turnover rates are evident for a wide range of prices and assumptions about cow performance.

Thus, if heifer prices were to decrease by $\$ 600$ and cull prices remained the same, these calculations show that rational, risk neutral dairy producers would increase their herd turnover rates by approximately 10 percentage units. If cull prices should decrease as well (driven more by beef market conditions), the herd turnover rate would increase less than 10 percentage units. It has been documented, however, that dairy producers often do not follow cow replacement recommendations (Miranda and Schnitkey, 1995; Rajala-Schultz and Gröhn, 2001).

Cull Cow Price. Currently, approximately 15 to $20 \%$ of the total US beef supply comes from the dairy industry. If sexed semen is partially adopted by some herds, there will likely be no significant measurable effect on beef cattle prices, even though increased herd turnover rates will increase the supply of cows that go to market. Widespread adoption of sexed semen may have a positive or negative effect on the value of an average dairy animal that goes to slaughter, depending on how it is used. If the majority of dairy producers select only the female sexed semen, the value of Holstein beef is likely to decline due to the feeding out of less feed efficient heifers as opposed to bulls or steers. In contrast, if dairy producers breed approximately $50 \%$ of their best heifers and cows to female sexed semen and use male sexed semen for the remaining cows, there is no net effect on the female vs. male population that goes to market. Consequently, there might be little effect on the cull cow price.

Milk Price. The milk price dairy producers receive is very sensitive to supply and demand. Widespread application of sexed semen is expected to accelerate the rate of expansion in growing herds as a result of lower prices for dairy replacement heifers. The cost of producing milk should therefore decrease. Initially, the supply of milk in the United States is expected to increase more than the demand. As a result, milk prices may decline until supply and demand stabilize again. Eventually, consumers should benefit from lower milk prices.

\section{Effect on Breeding Decisions on the Dairy Farm}

The availability of female dairy sexed semen means that fewer heifers and cows are needed as dams to produce the next generation of replacement heifer calves. Other animals may be bred to dairy conventional semen, nondairy sexed semen, and so on. This was foreseen 10 yr ago, when Foote (1996) discussed future prospects of dairy cattle reproductive management. He hypothesized that "large herds could be visualized to . . . synchronize a large group of top cows and to inseminate them with sexed sperm. Some cows might receive embryos produced by sexed sperm. Sperm and embryos could be produced by elite cattle selected in various MOET transfer schemes. . . . The rest of the herd would be inseminated with low cost, highly fertile sperm from bulls below the genetically elite group of bulls or receive sexed embryos produced in vitro."

The first question is which heifers or cows should receive dairy sexed semen to produce the next generation cows (Hohenboken, 1999). Approximately $60 \%$ of the breeding age heifers and cows would need to be bred with dairy female sexed semen if the resulting female calves are the only replacements to maintain the herd. Assuming reduced fertility of sexed semen compared with conventional semen, the recommendation has been that the primary candidates for sexed semen are heifers (Weigel, 2004) because they have greater fertility than cows (Garner and Seidel, 2003), female calves reduce the risk of dystocia (Seidel, 2003), and heifers are on average genetically superior to cows (Hohenboken, 1999).

Even if $90 \%$ of heifers calved with female calves, additional heifer calves from cows would be needed as replacements to replace all culled cows. These additional dairy heifer calves could be found from breeding cows with conventional dairy semen or genetically superior cows could be selected to be bred with sexed semen.

Cows chosen for insemination with female sexed semen should be the cows with the greatest PTA for an appropriate economic selection index or should be the cows with the greatest PTA for production traits if an economic selection index is not available. Similarly, breeding age heifers should be chosen based on their parent average (PA) for an economic selection index or on their PA for production traits if an economic selection index is not available. Dairy producers can use publicly available PTA for sires and maternal grandsires and essentially calculate an approximate PA for heifers in their herd by adding sire PTA plus one-half of the maternal grandsire PTA. In herds with good record keeping, cow production and performance records could be combined with PTA from sires (and maternal grandsires) to essentially calculate a farm-specific PTA. This can be done in a fairly crude way by using an index approach (Bourdon, 2000). Following this approach, it can be shown that a cow's own performance records, for example estimated 305-d milk yield in the first lactation, have only minor effects on her PTA if she is the daughter of a well-proven AI sire.

These farm-specific PTA will provide a much better ranking than just relying on the production records of the cow without any input from sires, especially if sires are proven AI sires. Rankings in herds with little pedigree information or in herds with cows sired by natural 
service bulls will not benefit much from adding sire information to each cow's own production information. In herds where only on-farm production information is available and cow pedigree information is not available, cow production information can be used to make the selection decisions. The uncertainty about cows' genetic merit will severely limit the potential genetic progress. For breeding age heifers with only information on the dam, managers can make decisions based on the dam's production information, but this is not very accurate. Therefore, sexed semen will increase the need for and the value of genetic information on heifers and cows. The combination of a higher probability of a female calf and the desire for more rapid genetic improvement should lead to the use of higher genetic merit sires, especially on commercial dairy farms.

Once it has been decided which heifers and cows will produce the dairy replacements, the remaining cows could be bred to inexpensive dairy or beef semen, depending on the value of the (possibly crossbred) calves. Marketability of crossbred animals may be difficult in the United States (Weigel and Barlass, 2003). One reason is that Holstein steers have gained acceptance in feedlots in the Southwest United States due to their predictable growth, feed conversion, and response to the hot, dry feedlot environment. Adding beef crosses contributes more variability within the feeding system and may negate some of the additional value potentially derived by improved carcass traits. On the other hand, beef $\times$ dairy crossbred calves have also been found more valuable for meat production than purebred dairy calves (Hohenboken, 1999). A smaller fraction of heifers and cows need to be bred to sexed semen if dairy conventional semen is used with the intent to keep resulting dairy female calves as replacements. Hohenboken (1999) discussed some breeding alternatives. Another option for the remaining cows would be not to rebreed them at all but maintain persistent lactations (Weigel, 2004; Rotz et al., 2005). The economically optimal breeding mix is farm-specific and depends on many factors, including genetic information on cows, risk of conception for each type of semen, quality of management and insemination skills, and prices (Fetrow et al., 2007; Seidel, 2007).

It is not clear what the interactions will be between the use of timed AI programs and sexed semen technology. Semen use increases in whole-herd synchronization programs. The availability of sexed semen could increase the use of timed $\mathrm{AI}$ when high conception risks are obtained, especially in herds with estrus detection problems. Because the success of timed AI programs is based upon the risk of conception and its cost, the reduced fertility and higher price of sexed semen are currently major limiting factors.

\section{Genetic Progress}

Without the widespread use of sexed semen, about 90 to $92 \%$ of all genetic change in milk yield has occurred from sire selection (Wilcox et al., 2003). Most of the genetic change from dam selection has been due to intense selection in the dams used to produce young sires, and this intense selection has been enhanced by embryo transfer. Annual genetic changes in milk yield, fat, protein, productive life, and daughter pregnancy rate in Holsteins born between 1980 and 2000 were on average $104 \mathrm{~kg}, 3.5 \mathrm{~kg}, 3.0 \mathrm{~kg}, 0.16 \mathrm{mo}$, and $-0.11 \%$, respectively (Shook, 2006). The increased use of sexed semen allows for more dam selection, but the effects on overall rate of genetic change are expected to be limited. First, selection intensity in males is much greater than in females. Only about $0.1 \%$ of all male calves born annually will be used as sires, whereas even with the widespread use of sexed semen, at least $60 \%$ of the breeding age females are needed to produce a sufficient number of replacements. Second, the accuracy of genetic merit estimates is much greater for sires than for dams. Proven sires will have information from many daughters, whereas dams seldom have information from any daughters. In addition, dams frequently do not have genetic information from their pedigree available.

Estimates of the effect of use of sexed semen on the rate of genetic change vary widely (Weigel, 2004). Collectively, the rate of genetic change has been expected to increase not more than $15 \%$ as a result of increased selection of dams through sexed semen (Hohenboken, 1999; Weigel, 2004).

\section{Economic Value of Sexed Semen to Dairy Producers}

Economic benefits of sexed semen may be obtained as a result of higher prices for female dairy calves compared with male dairy calves, the added value of (crossbred) calves not used as replacements, optimized herd turnover rates, reduced dystocia, increased rate of genetic progress, and possibly improved biosecurity if open herds could be closed. Added costs are higher semen price (Weigel, 2004) and greater cost of pregnancy diagnosis and ovulation synchronization as a result of the reduced fertility. In addition, there is some evidence that milk yield may be reduced in cows producing daughters compared with cows producing sons as a result of a positive association between birth weight and milk production (Hohenboken, 1999). An increased supply of heifers may also provide greater opportunity to cull poor growing heifers, thereby avoiding future losses as poor performing milking cows.

No studies are available that have incorporated all these aspects to determine the economic value of sexed 
semen in the United States. Results from studies that evaluated some aspects are not comparable because they used different values for key assumptions such as fertility of sexed semen and price of sexed semen compared with conventional semen. Ettema et al. (2007) explored the economic impact of sexed semen in Denmark.

Amann (1999) suggested that the added value of lowdose artificially inseminated sexed semen to a dairy producer should be at least 2 times the added cost (estimated at $\$ 30$ to $\$ 46$ higher price per unit with the then available sorters) before sexed semen would be widely adopted. This implies that the extra value of a unit of sexed semen should be $\$ 60$ compared with conventional semen.

In older studies, Taylor et al. (1988) concluded that the extra value of a unit of sexed semen was $\$ 5.81$ to $\$ 16.91$ compared with a unit of conventional, depending on the price of milk. Van Vleck and Everett (1976) reported a maximum extra value of $\$ 9.67$ per unit of sexed semen (prices not adjusted for inflation).

Weigel (2004) evaluated 3 breeding schemes with sexed semen that might have potential commercial application even when reduced fertility is assumed. The first scheme included the use of sexed semen on virgin heifers only. The extra cost per heifer calf, assuming $\$ 50$ greater cost per unit of sexed semen and reduced fertility compared with conventional semen, ranged from $\$ 47$ to $\$ 56$. A second scheme included in vitro embryo production from ovaries collected at the time of slaughter from genetically superior cows and fertilized with sexed semen. The extra cost per heifer calf ranged from $\$ 164$ to $\$ 207$ for recipient dairy cows and from $\$ 81$ to $\$ 118$ for recipient dairy heifers, assuming $\$ 50$ cost per embryo. The third possible scheme included the use of in vitro embryo production with ovaries from anonymous cows and sexed semen, but with beef cows as recipients. The extra cost per heifer calf ranged from $\$ 93$ to $\$ 171$, depending on probability of conception. Thus, if the additional value of a heifer calf compared with a male calf exceeds the extra cost to produce the heifer calf, then these breeding schemes are economically viable.

The use of sexed semen itself will initially cause a small increase in the cash cost of production because of the increase in the average semen price. For many dairy farms, there will also be increases in the cost of record keeping and perhaps labor to implement a somewhat more complex breeding scheme.

The widespread use of sexed semen should increase the supply of heifers, thereby reducing their purchase price. If only a reduction in heifer price from $\$ 1,900$ to $\$ 1,300$ per head is assumed, and herd turnover rate is $33 \%$, the extra profit would be over $\$ 200$ per slot per yr. Furthermore, a dairy farm producing more heifers by using sexed semen might convert cash profit into long term assets, thereby postponing taxes and converting ordinary income into capital gains.

\section{Increased Specialization}

If the purchase price of dairy heifers decreases as a result of increased supply, the economic benefits of raising heifers may be reduced for dairy producers. Under these conditions, some dairy producers might stop raising heifers and instead specialize in milking cows only. This is especially conceivable when environmental or water constraints limit the number of animals on a dairy farm. The choice to replace cows with heifers that were not born on the dairy farm will also affect the optimal breeding mix.

Heifer Raising. For many dairy farms, there is currently little opportunity to increase the number of heifers by using sexed semen without additional costs if those heifers are to be raised on the farm. Many dairy farms do not have the facilities, feed, labor, or capital needed to raise additional heifers. In addition, environmental regulations and permitting restrictions may mean that raising more heifers on site would require reducing the number of adult cows. In most circumstances, this would not be desirable.

Specialized heifer raising (growing) is expected to increase. If more heifer calves are produced as a result of the use of sexed semen, some calf raisers will be forced to make the transition from raising bull calves for the beef market to contract raising of dairy replacement heifer calves or speculative calf raising. This transition may be encouraged by a combination of decreased beef prices and a potential decrease in the number of bull calves that could result from adoption of sexed semen.

Genetic Foundation Farms. One conceivable new consequence of the use of sexed semen is that there might be a separation between dairy farms that own genetically superior animals, use female dairy sexed semen in all breedings, and sell excess heifers as superior genetic stock vs. other dairy farms that would breed their cows other than with female dairy sexed semen and purchase genetically superior replacement heifers. In this sense, the industry might tend to split into dairy farms that produce seed stock and dairy farms that purchase seed stock, similar to the current swine industry.

Organic Dairy Farms. Dairy farms that want to sell organic-labeled milk are bound by strict regulations. Once the soil management and nutritional practices have been altered to conform to organic methods, animals must be raised and managed under this system for an extended period of time to produce certified or- 
ganic-labeled milk. As a result, most of these herds are essentially closed. It is extremely difficult for such herds to expand because all replacements must be from a certified organic production system. As such, sexed semen technology offers an opportunity for organic herds to increase in herd size at a faster rate or to have the opportunity to market replacement heifers to organic herds that are expanding (assuming sexed semen remains allowed in organic dairy herds).

Biosecurity. Contrary to the drive for specialization, it has been argued that the widespread availability of sexed semen allows dairy producers to expand from within their closed herds by raising more heifers than they cull cows. Sufficient internal growth may reduce the amount of health problems caused by introduction of pathogens when animals from outside the dairy farm are brought in (Faust et al., 2001; Weigel, 2004). The economic value of biosecurity is not clear, however.

\section{Effect on Al Industry}

It is expected that sexed semen will be delivered almost exclusively through AI organizations. There will be costs associated with equipment, licensing, manufacturing, marketing, distribution, and delivery of sexed semen. These costs will be passed on to the dairy industry through higher prices for sexed semen.

Crossbreeding. If the value of a crossbred calf is greater than that of a purebred dairy calf, the market for beef sexed semen could be significant. Although some of the dairy AI organizations already sell beef semen, this is a new market opportunity. If male beef sexed semen is sold, there will be a need to collect information about performance of growth and feed efficiency of crossbred calves. The ability of an AI organization to rapidly collect and use these data might be a significant competitive advantage, especially because AI organizations have been unable to develop truly different genetic lines (Funk, 2006).

The current interest in crossbred lactating cows already stimulates AI organizations toward more focus on crossbreeding in the coming years (Funk, 2006). If a crossbreeding program is aimed at problem solving, such as for alleviation of dystocia, sexed semen may have limited impact. In a formal crossbreeding program, however, sexed semen could play a major role in rapidly advancing the progress of the plan.

Inbreeding. The average level of inbreeding for the major dairy breeds continues to increase (Funk, 2006). The application of sexed semen will likely accelerate the level of inbreeding, unless significant counteracting measures are taken. The increased use of sexed semen might work to raise the level of awareness of the problem of inbreeding due to the increased cost associated with the semen and create more demand for professional mating programs. Alternatively, sexed semen could be used to decrease inbreeding if that is a major goal.

Progeny Testing. More than 1,000 Holstein young sires are progeny-tested each year, but fewer than 100 graduate to proven sires (Funk, 2006). The cost of progeny testing a Holstein young sire ranges from $\$ 25,000$ to $\$ 35,000$ (Funk, 2006). Each young sire is allowed approximately 1,200 to 1,500 breedings, resulting in approximately 100 to 125 daughters that supply data for his test. If female sexed semen from young sires is widely used, the number of heifers and cows that need to be bred to prove a young sire would be reduced by $33 \%$. Consequently the cost of progeny test programs will be reduced.

Embryo Transfer. The majority of embryo transfer (ET) is from elite cows that have not been selected as bull mothers but with the desire of maximizing their impact on the genetic base of the dairy herd. Embryo transfer increases the availability of replacement heifers produced from elite cows compared with what would be available from routine AI or natural service bulls.

Almost all sires that are tested by AI organization are produced using ET or MOET. As cows of high genetic merit are identified, they are mated using ET to produce male calves from a number of desirable sires of sons to maximize the availability of bull calves from these matings for selection and entry into AI progeny testing programs as soon as possible. It is clear that sexed semen will have an impact on the use of ET in both the beef and dairy industries. The exact nature of this impact is not clear, however. In fact, there is considerable debate as to whether the impact will be to increase or decrease the use of ET in a particular sector.

Several studies document the lower probability of success of using sexed semen with superovulation (Schenk et al., 2006). But it is also clear that the use of sexed semen in ET will reduce the costs associated with using recipients and technology for embryos of the undesired sex.

Dairy producers with cows identified as having high genetic merit and selected as bull mothers may use male sexed semen to fulfill the request for bull calves for AI organizations as quickly as possible. They will also use sexed semen to get female calves from these cows to try to produce the next generation of bull mothers.

The combination of sexed semen and ET will improve the economic benefits of ET and open up new markets for use of many cows in dairy herds as recipients for both beef and dairy embryos. There may be a market for sexed embryos derived from slaughter harvested ova and in vitro fertilization because of the improved 
probability of conception for embryos vs. AI semen in cows. The limitation of available recipients has been a constraint for widespread use of ET between herds. The use of the bottom end cows in a dairy herd as recipients for known-sex calves from other beef or dairy herds should be considered.

On the other hand, the availability of sexed semen might reduce the use of ET in normal herd situations when sexed semen can be used on the best cows in the herd to increase the availability of high merit dairy replacement heifers without the expense and inconvenience of ET on just a few cows.

Genetic Markers. Genetic markers have been used extensively during the last $25 \mathrm{yr}$ to test animals early for harmful or lethal recessive genes. Bulls carrying such genes have been excluded from progeny testing programs by AI organizations. Selection for quantitative traits, for example milk production, has been minimally affected by genetic markers to date. Through the use of sexed semen, AI organizations might be able to better utilize genetic markers or important genes because they can produce more full-sibling individuals of the same sex. Currently, AI organizations do not have much opportunity to use markers or genes in selection because they do not have many full-sibling bull calves from the best sires and cows to choose from.

Genome Selection. In the future, male selection could be based on their genotypes, thereby potentially replacing the expensive and time-consuming process of progeny testing a young bull. Milk yield, fat yield, conformation score, mastitis status, calving ease, and other traits from the genotyped animals need to be correlated to specific single nucleotide polymorphism markers or groups of such markers. The use of sexed semen will greatly enhance the ability to make progress with these programs.

Consolidation. Consolidation of the AI industry, driven by the difficulty of differentiating genetic lines between AI organizations, is expected to continue (Funk, 2006). The widespread availability of sexed semen based on the same technology by the different AI organizations may quicken consolidation.

\section{Adoption Drivers}

The discussion thus far has focused on the structure of the dairy industry after sexed semen has been widely applied and its consequences have stabilized. Currently, the supply of sexed semen is limited, but demand exceeds supply. Even when sexed semen is widely used, it will take a minimum of almost $3 \mathrm{yr}$ before the first heifers born from sexed semen are ready to calve and enter the lactating herd.
Early adoption of sexed semen by dairy producers is likely to be primarily driven by heifer prices that are substantially higher than the cost to raise heifers. Early adoption will benefit dairy producers that demand and supply dairy heifers. Great price differences between female sexed semen and conventional semen will restrict its use to animals that are expected to have greater fertility, primarily, and are presumed to be genetically superior. Therefore, early use of sexed semen may be concentrated in nulliparous heifers and cows with very high genetic values. More moderate price differences and improvements in fertility will tend to expand the use toward the genetically average animals. The use will likely not expand beyond $60 \%$ of the population of cows and heifers because this would more than satisfy the entire need for replacement heifers.

Major adoption constraints include the past promises of the value of sexed semen that have failed to materialize (Weigel, 2004), primarily because of a history of compromised fertility of sexed semen and higher prices. Dairy producers are likely to want more information about the effects of sexed semen on embryonic losses, fetal deformities, abortions, and heifer health. Considering calves, Tubman et al. (2004) found that calves produced from sexed sperm grew and developed normally before and after calving. Furthermore, questions remain about how to best choose cows and sires for breeding with sexed semen, the optimal breeding mix for the remaining heifers and cows, and the quality of the required insemination technique. Dairy producers may try sexed semen on a small number of cows and by random chance receive fewer calves of the desired sex than was expected. This will cause doubt about the promises of the sexed semen technology. The higher price of sexed semen compared with conventional semen increases the financial risk associated with the breeding decision because conception is not guaranteed. Finally, some dairy producers will simply not be convinced that the value of sexed semen warrants the higher price. The value of sexed semen is reduced when milk prices, heifer prices, or cull cow prices are reduced, feed costs are greater, the price of conventional semen is reduced, or the price of beef crossbred calves compared with dairy purebred calves is reduced.

Cultural or emotional adoption constraints may exist as well or could quickly arise. New production technologies are not always welcome; consider for example the earlier resistance against AI, recombinant bovine somatotropin, dry cow therapy, and teat dipping, and the recently renewed resistance against recombinant bovine somatotropin. Part of the resistance is the expectation that the new technology will lead to an increase in the amount of milk produced in the United States and consequently lower farm milk prices. New effective 
production technologies accelerate the rate of consolidation in the dairy industry. Some consumers will see sexed semen as one more example of "manipulating nature" and will oppose its use. Advocacy groups may try to stimulate consumer concerns about genetically modified organisms or cloning. It is expected, however, that there will not be much consumer objection toward the use of sexed semen because there is no direct (perceived) effect on the quality of milk.

Postimplementation information on the average and variability of the actual sex ratios achieved with sexed semen could have a positive impact on dairy producer confidence, which is supported by a currently greater demand than supply. Furthermore, the negative correlation of earlier sexed semen technologies with conception risk could be discounted through an ongoing evaluation of reproductive performance with new sexed semen technologies, using accurate and reliable record management systems.

The majority of AI organizations offer some decision support programs for dam and sire selection. The objectives and methodology used in these services follow the individual breeding philosophy and goals of the dairy producer, and utilize all available active sires. These programs include the use of full-time professional mating evaluators with the intent of saving the dairy producer decision-making time, manage semen inventories, and improve consistency throughout the herd. There is no doubt that both professional mating program personnel and local AI technicians will have a profound effect on the rate of adoption of sexed semen and how it is used.

\section{CONCLUSIONS}

Sexed semen is expected to be widely used within the next decade because of continued improvements in fertility of sexed semen, increased sorting capacity, and competition between suppliers leading to better prices. The use of sexed semen is expected to affect the structure of the dairy industry by creating a greater supply of replacement heifers. Prices of replacement heifers will likely decrease to slightly above cost of production. As a result of less expensive replacement heifers, the typical herd will increase its herd turnover rate slightly. Because selection in dams is possible, the rate of genetic progress is expected to increase up to $15 \%$. The lower end of the herd may be bred to nondairy semen, but a market for crossbred calves is not well established. The rate of consolidation, expansion, and specialization of dairy farms may increase. The AI organizations may benefit from sexed semen by reduced cost of ET and progeny testing and better utilization of genetic markers. Early adopters of sexed semen technology may ben- efit most by selling surplus heifers at prices that are substantially higher than the cost to raise them or by increasing their replacement rates. The cost to produce milk and the price of milk will both likely be reduced, thereby passing the economic benefits of sexed semen on to consumers.

\section{ACKNOWLEDGMENTS}

Financial support was provided by Monsanto Dairy Business.

\section{REFERENCES}

Amann, R. P. 1999. Issues affecting commercialization of sexed sperm. Theriogenology 52:1441-1457.

Bourdon, R. M. 2000. Understanding Animal Breeding. 2nd ed. Prentice Hall, Upper Saddle River, NJ.

DairyBusiness Communications. 2007. Dairy Profit Weekly. Vol. 18, July 17.

De Vries, A. 2006. Economic value of pregnancy in dairy cattle. J. Dairy Sci. 89:3876-3885.

Ettema, J. F., D. L. Hoag, and G. E. Seidel. 2007. Economic opportunities for sexed semen on commercial dairies. WesternDairyNews. Vol. 7, No. 3.

Faust, M. A., M. L. Kinsel, and M. A. Kirkpatrick. 2001. Characterizing biosecurity, health, and culling during herd expansions. J. Dairy Sci. 84:955-965.

Fetrow, J., M. Overton, and S. Eicker. 2007. Sexed semen: Economics of a new technology. Pages 39-60 in Proc. 8th Western Dairy Management Conf., Reno, NV.

Foote, R. H. 1996. Review: Dairy cattle reproductive physiology research and management-Past progress and future prospects. J. Dairy Sci. 79:980-990.

Funk, D. A. 2006. Major advances in globalization and consolidation of the artificial insemination industry. J. Dairy Sci. 89:13621368.

Garner, D. L. 2006. Flow cytometric sexing of mammalian sperm. Theriogenology 65:943-957.

Garner, D. L., and G. E. Seidel. 2003. Past, present and future perspectives on sexing sperm. Can. J. Anim. Sci. 83:375-384.

Hohenboken, W. D. 1999. Applications of sexed semen in cattle production. Theriogenology 52:1421-1433.

Karzes, J. 2005. Dairy replacement programs: Costs and analysis. Pages 10-23 in Proc. from Dairy Calves and Heifers, Integrating Biology and Management. NRAES 175. Ithaca, NY.

Kiddy, C. A., and H. D. Hafs. 1971. Sex Ratio at Birth-Prospects for Control. Am. Soc. Anim. Sci., Champaign, IL.

Miranda, M. J., and G. D. Schnitkey. 1995. An empirical model of asset replacement in dairy production. J. Appl. Econometrics 10:S41-S55.

Moore, K., and W. W. Thatcher. 2006. Major advances associated with reproduction in dairy cattle. J. Dairy Sci. 89:1254-1266.

Rajala-Schultz, P. J., and Y. T. Gröhn. 2001. Comparison of economically optimized culling recommendations and actual culling decisions of Finnish Ayrshire cows. Prev. Vet. Med. 49:29-39.

Rotz, C. A., D. L. Zartman, and K. L. Crandall. 2005. Economic and environmental feasibility of a perennial cow dairy farm. J. Dairy Sci. 88:3009-3019.

Schenk, J. L., T. K. Suh, and G. E. Seidel. 2006. Embryo production from superovulated cattle following insemination of sexed sperm. Theriogenology 65:299-307.

Seidel, G. E. 2003. Economics of selecting for sex: The most important genetic trait. Theriogenology 59:585-598.

Seidel, G. E. 2007. Overview of sexing sperm. Theriogenology 68:443-446. 
Seidel, G. E., and D. L. Garner. 2002. Current status of sexing mammalian spermatozoa. Reproduction 124:733-743.

Shook, G. E. 2006. Major advances in determining appropriate selection goals. J. Dairy Sci. 89:1349-1361.

Taylor, J. F., K. R. Phillips, and M. A. Tomaszewski. 1988. Net present value and economic merit of sexed semen and splitting units of semen for Australian Holsteins. J. Dairy Sci. 71:3100-3111.

Tozer, P., M. Gabler, T. Schriefer, and J. Heinrichs. 1999. Heifer economics. Penn State Univ. Ext. Publ. DAS 99-14. http:// www.das.psu.edu/dairy/documents/heiferecon.pdf Accessed Nov. 20, 2007.

Tubman, L. M., Z. Brink, T. K. Suh, and G. E. Seidel Jr. 2004. Characteristics of calves produced with sperm sexed by flow cytometry/cell sorting. J. Anim. Sci. 82:1029-1036.
USDA-NASS. 2007. "Milk production" Report. Released Jan. 18, 2007. http://usda.mannlib.cornell.edu/usda/nass/MilkProd// 2000s/2007/MilkProd-01-18-2007.pdf Accessed Nov. 20, 2007.

Van Vleck, L. D., and R. W. Everett. 1976. Genetic value of sexed semen to produce dairy heifers. J. Dairy Sci. 59:1802-1807.

Weigel, K. A. 2004. Exploring the role of sexed semen in dairy production systems. J. Dairy Sci. 87(E. Suppl.):E120-E130.

Weigel, K. A., and K. A. Barlass. 2003. Results of a producer survey regarding crossbreeding on US dairy farms. J. Dairy Sci. 86:4148-4154.

Wheeler, M. B., J. J. Rutledge, A. Fischer-Brown, T. VanEtten, S. Malusky, and D. J. Beebe. 2006. Application of sexed semen technology to in vitro embryo production in cattle. Theriogenology 65:219-227.

Wilcox, C. J., D. W. Webb, and M. A. DeLorenzo. 2003. Genetic improvement in dairy cattle. Univ. Florida Ext. Publ. DS75. http://edis.ifas.ufl.edu/DS094 Accessed Nov. 20, 2007. 